\title{
Penerapan Keselamatan dan Kesehatan Kerja (K3) di Beberapa Rumah Sakit Indonesia
}

\author{
Najla Asyah Syafawani Lubis/191101010 \\ najlaasyahsyafawani@gmail.com
}

\section{Latar Belakang}

Rumah Sakit mempunyai banyak potensi bahaya yang dapat mengancam jiwa dan kehidupan khususnya untuk karyawan di rumah sakit, para pasien dan para pengunjung yang ada di lingkungan rumah sakit (Kemenkes 2007). Rumah Sakit sebagai industri jasa pelayanan kesehatan, merupakan lembaga yang padat modal, pada teknologi, dan padat sumber daya manusia yang dalam prosesnya banyak mengandung potensi bahaya seperti, bahaya pemajanan radiasi, bahan kimia toksik, temperatur ekstrim,ergonomik, dan sebagainya, dapat menimpa pekerja apabila tidak ditanggulangi dengan baik dan benar dapat menimbulkan dampak negatif terhadap keselamatan dan kesehatan pekerja (Novi Erniwati, 2017).

Keselamatan dan kesehatan kerja rumah sakit adalah kegiatan untuk menjamin dan melindungi keselamatan dan kesehatan bagi sumber daya manusia rumah sakit, pasien, pendamping pasien, sehingga dibuat standar perlindungan bagi pekerja yang ada di rumah sakit untuk mencegah dan mengurangi risiko bahaya tersebut. Standar kesehatan dan keselamatan kerja di Rumah Sakit k3rs perlu ditetapkan untuk mencegah dan mengurangi resiko kecelakaan dan penyakit akibat kerja di Rumah Sakit. Demi terciptanya jaminan keselamatan kerja maka diperlukan pelayanan strategis yang profesional serta prosedur kerja yang tetap, tidak hanya tergantung pada peraturanperaturan yang mengayomi nya dan finansial yang diberikan, melainkan banyak faktor yang harus ikut terlibat, diantaranya adalah pelaksanaan organisasi. Suatu organisasi yang berhasil dapat diukur dengan melihat pada sejauh mana organisasi tersebut dapat mencapai tujuannya. Pelaksanaan K3 di rumah sakit dapat dinilai dari keefektivitasan organisasi K3 tersebut (Kun Dwi Apriliawati, 2017).

Keselamatan dan kesehatan kerja rumah sakit merupakan program yang baru bagi rumah sakit di Indonesia, hanya ada beberapa rumah sakit yang memiliki panitia k3rs, dan itu pun belum memiliki program yang terarah Oleh karena itu Rumah Sakit dituntut untuk melaksanakan upaya 
keselamatan dan kesehatan kerja (K3) yang dilaksanakan secara terintegrasi dan menyeluruh sehingga resiko terjadinya penyakit akibat kerja (PAK) dan kecelakaan akibat kerja (KAK) di rumah sakit dapat dihindari (Alimudin, 2010). Keputusan Menteri Kesehatan No. 432 tahun 2007 tentang pedoman manajemen K3 di rumah sakit menjelaskan bahwa rumah sakit mempunyai banyak potensi bahaya yang mengancam jiwa dan kehidupan bagi para karyawan di rumah sakit, para pasien maupun para pengunjung yang ada di rumah sakit.

\section{Metode}

Rancangan penugasan kajian ini menggunakan metode literatur review. Dimana metode ini dapat menyelesaikan suatu masalah dengan mengumpulkan data, menganalisa, membandingkan sehingga dapat menentukan pengambilan keputusan dalam masalah tersebut yang berdasarkan dari penjelasan sumber dan referensi yaitu berupa jurnal, ebook atau buku teks.

\section{Hasil}

Pada hasil penelitian Riska Nazirah dan Yuswardi, 2017. Di dapat pada tahun 2015 di rumah sakit umum daerah dr. Zainoel Abidin Banda Aceh telah terjadi 19 kasus kecelakaan kerja. Rincian kasus yang didapat dimana 18 kasus terjadi pada perawat yaitu 13 orang perawat tertusuk jarum, 2 orang terpapar cairan tubuh, 1 orang terpapar cairan B3 (obat kemoterapi), dan dua orang terpeleset sedangkan 1 kasus lainnya terjadi pada petugas pemeliharaan sarana yang terluka akibat terlepasnya tutup tabung oksigen. Ketua Komite kesehatan dan keselamatan kerja rumah sakit k3rs juga meyakini bahwa masih banyak kasus-kasus kecelakaan kerja lainnya yang tidak dilaporkan kepada pihak rumah sakit. Pihak rumah sakit sudah mulai menerapkan standar kesehatan dan keselamatan kerja rumah sakit k3rs Sesuai dengan keputusan Menteri Kesehatan Republik Indonesia Nomor 1087 tahun 2010 namun pelaksanaannya belum begitu optimal.

Pada hasil penelitian Hana Ike Dameria Purba, 2018. K3RS di Rumah Sakit Umum Mitra Sejati Medan sudah berjalan sekitar 5 tahun. Pada tahun 2018, diketahui bahwa berdasarkan data kecelakaan kerja di Rumah Sakit Mitra Sejati Medan adalah sebanyak 6 orang untuk kasus tertentu yaitu pada bulan Januari yang terkena jarum suntik sebanyak 1 orang, sedangkan pada bulan Februari sampai dengan Mei tidak ada terjadi kecelakaan kerja, pada bulan Juni terjadi kembali kecelakaan kerja sebanyak 2 orang, 1 orang terkena jarum suntik dan 1 orang terkena nald hecting, untuk bulan Juli sampai September tidak ada kejadian kecelakaan kerja. Menurut 
data tersebut dapat diketahui bahwa kondisi penerapan studi k3rs berdasarkan penelitian ini masih belum menunjukkan kondisi yang optimal.

Pada hasil penelitian Ezra Zimri, 2020. Menyatakan bahwa hasil wawancara dengan responden. Responden yang mempunyai tindakan yang baik terhadap penerapan K3 rumah sakit, sebanyak $56,7 \%$ hasil pengamatan di lapangan yaitu pada saat bekerja responden menggunakan APD seperti handskun, masker dan penutup kepala bagi setiap tenaga kesehatan yang memberikan pelayanan di dalam ruangan, dan responden sebagai petugas kebersihan menggunakan sarung tangan, topi sebagai penutup kepala, sarung tangan dan masker, hal itu digunakan untuk mencegah terjadinya infeksi nosokomial di lingkungan rumah sakit.

Hasil penelitian yang dilakukan oleh Sri Nurfitriani pada tahun 2012 di RSUD ajappange Soppeng menunjukkan penerapan standar pelayanan kesehatan pencapaian standar sebesar $59,9 \%$ ini termasuk ke dalam kategori terlaksana kurang baik. Penerapan standar pelayanan untuk keselamatan kerja pencapaian standar sebesar 78,6\% ini masuk ke dalam kategori terlaksana sangat baik. Sosialisasi terhadap dibutuhkan di rumah sakit ini untuk menanamkan seluruh pekerja tentang pentingnya pelaksanaan K3 sehingga melaksanakan program dengan kemauan bukan karena hal itu aturan Semata.

Pada hasil penelitian yang dilakukan oleh Putri Elshadai, 2019. Didapat penerapan kesehatan dan keselamatan kerja di Rumah Sakit Bhayangkara TK III Manado tergolong sudah baik, tetapi walau sudah baik perlu dilakukan Penyuluhan tentang pengetahuan K3 pada perawat yang masih terdapat perawat yang memiliki pengetahuan kurang baik agar bisa menambah wawasan dan meningkatkan pengetahuan tentang K3 serta perlu dilakukan pelatihan K3 sehingga dapat mengetahui jalur evakuasi yang benar dan tepat pada saat terjadinya kejadian di rumah sakit dan turut membantu dalam evakuasi ketika terjadi bencana atau kebakaran saat bekerja.

Pada hasil penelitian yang dilakukan oleh Tatilu 2017 di RSUD Dr. Sam Ratulangi Tondano menunjukkan bahwa untuk kebijakan K3 di rumah sakit yang telah ada yaitu pembentukan tim k3rs dan mengadakan anggaran, namun masih kurangnya koordinasi dari pihak manajemen, tim k3rs dan tenaga kesehatan. Untuk perencanaan sudah memuat tujuan dan sasaran K3 yang terdapat indikator pengukuran dan sasaran pencapaian akan tetapi belum maksimal. 
Pada hasil penelitian Hasbi Ibrahim, 2017. Rumah Sakit Umum Daerah Haji Makassar telah melakukan pelayanan keselamatan dan kesehatan kerja dengan baik. Pihak rumah sakit umum daerah Haji Makassar telah melakukan kegiatan pemeriksaan kesehatan terhadap pegawainya, pemeriksaan tersebut dilakukan sebelum petugas masuk, pemeriksaan setiap 6 bulan, pemeriksaan khusus, dan pemeriksaan paripurna, tetapi proses pencatatan dan pendataan belum dilaksanakan dengan baik.

Berdasarkan data dan fakta pada paragraf- Paragraf sebelumnya maka potensi bahaya di rumah sakit sangat tinggi sehingga dibutuhkan langkah Manajemen untuk mengontrol seluruh tenaga kerja supaya terhindar dari hal yang tidak diharapkan. Penerapan manajemen keselamatan dan kesehatan kerja rumah sakit (MKERS) menjadi sangat penting dalam rangka melindungi seluruh pekerja dari kecelakaan kerja dan penyakit akibat kerja di rumah sakit. Berdasarkan data dan fakta pada paragraph sebelumnya didapat bahwa penerapan keselamatan dan kesehatan kerja (K3) di beberapa rumah sakit Indonesia belum begitu optimal dan masih perlu perbaikan.

\section{Pembahasan}

Rumah Sakit merupakan sarana pelayanan yang bergerak di bidang pelayanan jasa kesehatan. Pelayanan rumah sakit merupakan bagian yang tidak terpisah dari sistem pelayanan kesehatan pada umumnya. Dalam pemberian pelayanan kesehatan Rumah Sakit diharapkan dapat memberikan pelayanan yang berkualitas. Potensi bahaya di rumah sakit dapat disebabkan oleh faktor biologi, faktor kimia, faktor ergonomi, faktor fisik, faktor psikososial, bahaya mekanik, bahaya listrik, limbah rumah sakit yang dapat mengancam jiwa dan kehidupan bagi para karyawan Rumah Sakit, pasien maupun para pengunjung yang ada di lingkungan rumah sakit yang mengakibatkan penyakit dan kecelakaan akibat kerja (azza ivana dkk, 2014).

Kesehatan dan keselamatan kerja atau K3 merupakan suatu upaya perlindungan kepada Tenaga Kerja dan orang lain yang memasuki tempat kerja terhadap bahaya dari akibat kecelakaan kerja. Tujuan K3 adalah mencegah, mengurangi, bahkan menihilkan resiko penyakit dan kecelakaan akibat kerja (KAK) serta meningkatkan derajat kesehatan para pekerja sehingga produktivitas kerja meningkat. Dalam undang-undang Republik Indonesia nomor 36 tahun 2009 tentang kesehatan, upaya kesehatan kerja ditujukan untuk melindungi pekerja agar hidup sehat dan terbebas dari gangguan kesehatan serta pengaruh buruk yang diakibatkan oleh pekerjaan 
sehingga sudah seharusnya pihak pengelola Rumah Sakit menerapkan upaya-upaya K3 di rumah sakit. K3 termasuk sebagai salah satu standar pelayanan yang dinilai di dalam akreditasi rumah sakit, di samping standar pelayanan lainnya.

Pekerja rumah sakit mempunyai resiko lebih tinggi dibandingkan pekerja industri lain untuk terjadinya penyakit akibat kerja (PAK) dan KAK. Sehingga perlu dibuat standar perlindungan bagi pekerja yang ada di rumah sakit. Untuk mencegah dan mengurangi resiko bahaya tersebut maka perlu ditetapkan standar K3 di rumah sakit. Perlunya pelaksanaan k3rs mengenai kebijakan pemerintah tentang rumah sakit di Indonesia adalah untuk meningkatkan akses, keterjangkauan, dan kualitas pelayanan kesehatan yang aman di rumah sakit. Perencanaan, pelaksanaan, monitoring, dan evaluasi k3rs serta tindak lanjut, yang merujuk pada SK Menkes no. 432/Menkes/SK/1V/2007 tentang pedoman manajemen K3 di rumah sakit dan OHSAS 18001 tentang standar sistem manajemen K3. Sistem manajemen K3 RS adalah bagian dari sistem manajemen rumah sakit.

Pelaksanaan K3, berkaitan dengan Citra dan kelangsungan hidup rumah sakit. Manajemen adalah proses perencanaan, pengorganisasian, pengarahan dan pengawasan usaha para anggota organisasi dan pengunaan sumber daya organisasi lainnya agar mencapai tujuan organisasi yang telah ditetapkan. Kementerian Kesehatan Republik Indonesia mewajibkan dilaksanakannya akreditasi rumah sakit yang bertujuan untuk meningkatkan pelayanan rumah sakit di Indonesia. Standar akreditasi yang digunakan saat ini akan menekankan pada pelayanan berfokus pada pasien serta kesinambungan pelayanan dan menjadikan keselamatan pasien sebagai standar utama serta melibatkan seluruh petugas dalam proses akreditasi.

Penerapan keselamatan dan kesehatan kerja rumah sakit pada tenaga kesehatan salah satunya adalah perawat. persepsi perawat tentang K3 menunjukkan bagaimana perawat mampu mencari tahu tentang pentingnya K3 baik melalui brosur, leaflet, SOP yang disediakan di ruangan maupun media informasi lainnya. perawat juga dituntut untuk paham bagaimana cara pencegahan kecelakaan serta penanganan yang dapat dilakukan apabila kita akan terjadi. pemahaman tersebut akan menimbulkan persepsi yang baik dalam diri perawat tentang K3 sehingga hal ini akan meningkatkan perilakunya dalam menjaga keselamatan. Selain persepsi, sikap juga mempengaruhi perilaku perawat ditinjau dari segi faktor internal seorang perawat dapat melaksanakan manajemen K3 harus memiliki sikap yang sesuai dengan nilai-nilai 
kesehatan di mana seluruh nilai positif yang ada dalam dirinya menjadi pendorong perilaku sehat dan menjadi upaya dalam meningkatkan kesehatan dan keselamatan selama bekerja. Selain faktor internal, faktor eksternal juga dapat mempengaruhi perilaku perawat dalam penerapan manajemen K3 di rumah sakit. Peneliti berasumsi bahwa ada banyak faktor yang dapat menentukan perubahan perilaku perawat dari segi faktor eksternal, diantaranya pengalaman titik pengalaman perawat dapat dilihat dari berbagai aspek titik salah satunya adalah masa kerja. semakin lama masa kerja perawat maka semua pengalaman yang dimiliki juga semakin meningkat sehingga perilakunya dapat menjaga keselamatan dirinya juga menjadi lebih baik. selain itu pengalaman juga dapat diperoleh dari berbagai sosialisasi maupun pelatihan tentang K3 yang dilakukan oleh pihak rumah sakit. faktor selanjutnya yang ikut berperan dalam perubahan perilaku perawat yaitu tersedianya fasilitas yang mendukung sesuai dengan standar yang telah ditentukan. Selain beberapa faktor diatas, budaya organisasi juga berpengaruh terhadap perilaku perawat dalam melaksanakan keselamatan, gimana budaya organisasi yang baik akan mendorong perawat untuk bekerja sesuai dengan prosedur yang telah ditentukan (Notoadmodjo, 2010).

Pada jurnal KESMAS Ferlina dkk, 2019. Ada beberapa pelaksanaan program K3RS yaitu: pengembangan kebijakan K3RS, pembudidayaan perilaku K3RS, pengembangan SDM, pelayanan kesehatan kerja, pelayanan keselamatan kerja, pemantauan kesehatan lingkungan kerja, pengembangan manajemen tanggap darurat, pengembangan pedoman, petunjuk teknis dan sop, pengembangan program pemeliharaan pengolahan limbah padat, cair dan gas, pengelolaan jasa, bahan beracun berbahaya dan barang berbahaya, pengumpulan data pengolahan dan pelaporan K3RS, dan review program tahunan, Rumah Sakit melakukan akreditasi sesuai dengan Permenkes RI No 34 tahun 2017 tentang akreditasi Rumah Sakit.

Pencegahan kecelakaan kerja dapat dilakukan dengan (1) pengamatan resiko bahaya di tempat kerja, (2) pelaksanaan SOP secara benar di tempat kerja, (3) pengendalian faktor bahaya di tempat kerja, (4) peningkatan pengetahuan tenaga kerja terhadap keselamatan kerja dan (5) pemasangan peringatan bahaya kecelakaan di tempat kerja. Selain itu upaya pencegahan kecelakaan kerja juga perlu disediakan sarana untuk menanggulangi kecelakaan di tempat kerja seperti penyediaan P3K, penyediaan peralatan dan perlengkapan tanggap darurat (Cecep, 2014). Sangat penting penerapan Keselamatan dan Kesehatan Kerja (K3) di rumah sakit Indonesia ini. Dari hasil yang didapat bahwa pada beberapa Rumah Sakit Indonesia sudah menerapkan sistem 
Manajemen Keselamatan dan Kesehatan Kerja di rumah sakit, namun masih banyak yang belum menerapkannya secara optimal. Oleh karena itu perlu banyak perbaikan di rumah sakit- rumah sakit yang ada di Indonesia.

\section{Kesimpulan}

Keselamatan dan kesehatan kerja adalah upaya untuk memberikan jaminan kesehatan dan meningkatkan derajat kesehatan para pekerja dengan cara pencegahan kecelakaan dan penyakit akibat kerja, pengendalian bahaya di tempat kerja, promosi kesehatan, pengobatan dan rehabilitasi titik peran kesehatan dan keselamatan kerja dalam ilmu kesehatan berkontribusi dalam upaya perlindungan kesehatan para pekerja dengan upaya promosi kesehatan, pemantauan, dan survei kesehatan serta upaya peningkatan daya tahan tubuh dan kebugaran pekerja. Sementara peran keselamatan adalah menciptakan sistem kerja yang aman atau yang mempunyai potensi Resiko yang rendah terhadap terjadinya kecelakaan. Pelaksanaan keselamatan dan kesehatan kerja K3 adalah salah satu bentuk upaya untuk menciptakan tempat kerja yang aman, sehat, dan bebas dari pencemaran lingkungan, sehingga dapat mengurangi dan bebas dari kecelakaan kerja dan penyakit akibat kerja yang pada akhirnya dapat meningkatkan efisiensi dan produktivitas kerja.

\section{Daftar Pustaka}

Ernawati, N., Nurlelawati, E. (2017). Faktor-Faktor yang Berhubungan denagn Pelaksanaan Penerapan K3 pada Tenaga Kesehatan di RSIA Permata Sarana Husada. Jurnal Akademi Keperawatan Husada Karya Jaya, 3 (1), 12-17.

Ibrahim, H., Damayanti, D, S., Amansyah, M., Sunandar. (2017). Gambaran Penerapan Standar Menejemen Keselamatan dan Kesehatan Kerja Rumah Sakit di Rumah Sakit Umum Daerah Haji Makasar. Public Health Science Journal, 9 (2), 160-172.

Ivana, A., Widjasena, B., Jayanti, S. (2014). Analisa Komitmen Menejemen Rumah Sakit (RS) Terhadap Keselamatan dan Kesehatan Kerja (K3) pada RS Prima Medika Pemalang. Jurnal Kesehatan Masyarakat, 2 (1), 35-40. 
Kumayas, P, E., Kawatu, P, A., Warouw, F. (2019). Hubungan Pengetahuan dan Sikap dengan Penerapan Kesehatan dan Keselamatan Kerja (K3) pada Perawat Di Rumah Sakit Bhayangkara TK II Manado. Jurnal KESMAS, 8 (7), 366-371.

Mantiri, E, Z., Pinontoan, O, R., Mandey, S. (2020). Faktor Psikologi dan Perilaku dengan Penerapan Menejemen Keselamtan dan Kesehatan Kerja Rumah Sakit. Indonesia Journal of Public Health and Community Medicine, 1 (3), 19-26.

Maringka, F., Kawatu, P, A., Punuh, M, I. (2019). Analisis Pelaksanaan Program Kesehatan dan Keselamatan Kerja di Rumah Sakit Tingkat II Robert Wolter Mongisidi Kota Manado. Jurnal KESMAS, 8 (5), 1-10.

Nazirah, R., Yuswardi. (2017). Perilaku Perawat dalam Penerapan Manajemen Kesehatan dan Keselamatan Kerja (K3) Di Aceh. Idea Nursing Journal, 8 (3).

Olii, G., Pinontoan, O, R., Kawatu, P, A. (2019). Gambaran Penerapan Standar Pelayanan Keselamatan dan Kesehatan Kerja Rumah Sakit (K3RS) di RSUD Datoe Binangkang Kabupaten Bolaang Mongondow. Jurnal KESMAS, 8 (6).

Purba, H, I., Girsang, V, I., Malay, U, S. (2018). Studi Kebijakan Perencanaan dan Pelaksanaan Keselamatan dan Kesehatan Kerja Rumah Sakit (K3RS) di Rumah Sakit Umum Mitra Sejati Medan. Jurnal Mutiara Kesehatan Masyarakat, 3 (2), 113-123.

Putri, S., Rahayu, E, P. (2018). Pelaksanaan Keselamatan dan Kesehatan Kerja Terhadap Kejadian Kecelakaan Kerja Perawat Rumah Sakit. Jurnal Endurance, 3(2), 271-277.

Simamora, R. H. (2018). Buku ajar keselamatan pasien melalui timbang terima pasien berbasis komunikasi efektif: SBAR. Medan: USUpress.

Simamora, R. H. (2019). Buku ajar pelaksanaan identifikasi pasien. Uwais Inspirasi Indonesia. 